Marquette University

e-Publications@Marquette

7-1999

\title{
Models for Molybdenum Coordination during the Catalytic Cycle of Periplasmic Nitrate Reductase from Paracoccus denitrificans Derived from EPR and EXAFS Spectroscopy
}

\author{
Clive S. Butler \\ University of East Anglia \\ John M. Charnock \\ University of Manchester \\ Brian Bennett \\ Marquette University, brian.bennett@marquette.edu \\ Heather J. Sears \\ University of Oxford \\ Ann J. Reilly \\ University of East Anglia
}

See next page for additional authors

Follow this and additional works at: https://epublications.marquette.edu/physics_fac

Part of the Chemistry Commons, and the Physics Commons

\begin{abstract}
Recommended Citation
Butler, Clive S.; Charnock, John M.; Bennett, Brian; Sears, Heather J.; Reilly, Ann J.; Ferguson, Stuart J.; Garner, C. David; Lowe, David J.; Thomson, Andrew J.; Berks, Ben C.; and Richardson, David J., "Models for Molybdenum Coordination during the Catalytic Cycle of Periplasmic Nitrate Reductase from Paracoccus denitrificans Derived from EPR and EXAFS Spectroscopy" (1999). Physics Faculty Research and Publications. 53.

https://epublications.marquette.edu/physics_fac/53
\end{abstract}




\section{Authors}

Clive S. Butler, John M. Charnock, Brian Bennett, Heather J. Sears, Ann J. Reilly, Stuart J. Ferguson, C. David Garner, David J. Lowe, Andrew J. Thomson, Ben C. Berks, and David J. Richardson 
Marquette University

e-Publications@Marquette

Physics Faculty Research and Publications/College of Arts and Sciences

This paper is NOT THE PUBLISHED VERSION; but the author's final, peer-reviewed manuscript. The published version may be accessed by following the link in the citation below.

Biochemistry, Vol. 38, No. 28 (1 July 1999): 9000-9012. DOI. This article is (C American Chemical Society Publications and permission has been granted for this version to appear in $\underline{\mathrm{e}}-$ Publications@Marquette. American Chemical Society Publications does not grant permission for this article to be further copied/distributed or hosted elsewhere without the express permission from American Chemical Society Publications.

\section{Models for Molybdenum Coordination during the Catalytic Cycle of Periplasmic Nitrate Reductase from Paracoccus denitrificans Derived from EPR and EXAFS Spectroscopy}

Clive S. Butler

School of Biological Sciences and School of Chemical Sciences, University of East Anglia, Norwich, NR4 7TJ, U.K.

John M. Charnock

Daresbury Laboratory, Warrington, WA4 4AD, U.K.

Department of Chemistry, University of Manchester, Manchester, M13 9PL, U.K.

Brian Bennett

Daresbury Laboratory, Warrington, WA4 4AD, U.K. 


\title{
Heather J. Sears
}

Department of Biochemistry, University of Oxford, Oxford, OX1 3QU, U.K.

Ann J. Reilly

School of Biological Sciences, University of East Anglia, Norwich, NR4 7TJ, U.K.

Stuart J. Ferguson

Department of Biochemistry, University of Oxford, Oxford, OX1 3QU, U.K.

\section{David Garner}

Department of Chemistry, University of Manchester, Manchester, M13 9PL, U.K.

\section{David J. Lowe}

Nitrogen Fixation Laboratory, John Innes Centre, Colney Lane, Norwich, NR4 7UH, U.K.

\section{Andrew J. Thomson}

School of Chemical Sciences, University of East Anglia, Norwich, NR4 7TJ, U.K.

\section{Ben C. Berks}

School of Biological Sciences, University of East Anglia, Norwich, NR4 7TJ, U.K.

David J. Richardson

School of Biological Sciences, University of East Anglia, Norwich, NR4 7TJ, U.K.

\section{SUBJECTS:}

Azides, Anions, Peptides and proteins, Ligands

\begin{abstract}
The periplasmic nitrate reductase from Paracoccus denitrificans is a soluble two-subunit enzyme which binds two hemes (c-type), a [4Fe-4S] center, and a bis molybdopterin guanine dinucleotide cofactor (bis-MGD). A catalytic cycle for this enzyme is presented based on a study of these redox centers using electron paramagnetic resonance (EPR) and extended X-ray absorption fine structure (EXAFS) spectroscopies. The Mo(V) EPR signal of resting NAP (High $g$ [resting]) has $g_{\mathrm{av}}=1.9898$ is rhombic, exhibits low anisotropy, and is split by two weakly interacting protons which are not solvent-exchangeable. Addition of exogenous ligands to this resting state (e.g., nitrate, nitrite, azide) did not change the form of the signal. A distinct form of the High $g \mathrm{Mo}(\mathrm{V})$ signal, which has slightly lower anisotropy and higher rhombicity, was trapped during turnover of nitrate and may represent a catalytically relevant Mo(V) intermediate (High $g$ [nitrate]). Mo K-edge EXAFS analysis was undertaken on the ferricyanide oxidized enzyme, a reduced sample frozen within $10 \mathrm{~min}$ of dithionite addition, and a nitratereoxidized form of the enzyme. The oxidized enzyme was fitted best as a di-oxo Mo(VI) species with 5 sulfur ligands ( 4 at $2.43 \AA$ and 1 at $2.82 \AA$ ), and the reduced form was fitted best as a mono-oxo Mo(IV) species with 3 sulfur ligands at $2.35 \AA$. The addition of nitrate to the reduced enzyme resulted in reoxidation to a di-oxo Mo(VI) species similar to the resting enzyme. Prolonged incubation of NAP with dithionite in the absence of nitrate (i.e., nonturnover conditions) resulted in the formation of a species with a Mo(V) EPR signal that is quite distinct from the High $g$ family and which has a $g_{\mathrm{av}}=1.973$ (Low $g$ [unsplit]). This signal resembles those of the mono-MGD xanthine oxidase family and is proposed to arise from an inactive form of the nitrate reductase in which the $\mathrm{Mo}(\mathrm{V})$ form is only coordinated by the dithiolene of one MGD. In samples of NAP that had been reduced with dithionite, treated with azide or cyanide, and then reoxidized with ferricyanide, two Mo(V) signals were detected with $g_{\mathrm{av}}$ elevated compared to the High $g$ signals. Kinetic analysis demonstrated that azide and cyanide
\end{abstract}


displayed competitive and noncompetitive inhibition, respectively. EXAFS analysis of azide-treated samples show improvement to the fit when two nitrogens are included in the molybdenum coordination sphere at 2.52 $\AA$, suggesting that azide binds directly to Mo(IV). Based on these spectroscopic and kinetic data, models for Mo coordination during turnover have been proposed.

This work was supported by BBSRC Grant GrCO8666 to D.J.R., B.C.B., A.J.T., and S.J.F. and BBSRC Grant BO30321 to the Centre for Metalloprotein Spectroscopy and Biology, University of East Anglia. D.J.R. acknowledges the BBSRC for funding study leave with D.J.L. at the Nitrogen Fixation Laboratory.

The bacterial reduction of nitrate to nitrite can be carried out by three distinct enzymes. Two enzymes are associated with energy-conserving respiratory electron-transport pathways and one with nitrate assimilation (1). One of the respiratory enzymes is membrane-anchored with an active site in the cytoplasm, and the other is a water-soluble periplasmic enzyme (2). The assimilatory enzymes are located in the cytoplasm (1). Sequence analysis has led to the conclusion that all the bacterial nitrate reductases are members of the subgroup of molybdoenzymes that bind the molybdopterin guanine dinucleotide (MGD) ${ }^{1}$ form of the molybdopterin cofactor (2). The soluble periplasmic nitrate reductase (NAP) from Paracoccus denitrificans [previously classified as Thiosphaera pantotropha (3)] contains a $16 \mathrm{kDa}$ di-heme $c$-type cytochrome subunit (NapB) and an $80 \mathrm{kDa}$ catalytic subunit (NapA) that binds an N-terminal [4Fe-4S] cluster and the MGD $(2,4-6)$. The catalytic subunit exhibits a high degree of sequence similarity to the MGD-binding polypeptides of bacterial assimilatory nitrate reductases (NAS) and formate dehydrogenases, both of which also bind an N-terminal iron-sulfur cluster and $\operatorname{MGD}(2,7)$. NAP and NAS are quite distinct from the membrane-bound nitrate reductase (NAR), which is a three-subunit enzyme consisting of an integral membrane di-b-heme cytochrome, a water-soluble electrontransferring subunit that binds four iron-sulfur clusters, and a large $140 \mathrm{kDa}$ catalytic subunit that binds the MGD (2).

The recently reported crystal structure of monomeric NapA from Desulfovibrio desulfuricans has revealed the presence of two MGD moieties per polypeptide (bis-MGD) (8). This is consistent with crystal structures of three other members of the MGD family, namely, the soluble periplasmic DMSO reductases (DMSOR) from Rhodobacter capsulatus and Rhodobacter sphaeroides, the soluble formate dehydrogenase $\mathrm{H}$ (FdhH) from Escherichia coli, and the periplasmic TMAO reductase from Shewanella massilia (9-13). These two MGD moieties can provide up to four thiolate ligands to the Mo, although in the case of one structure of the DMSO reductase the di-thiol of one MGD moiety is not coordinated to the Mo (10). This indicates some flexibility in the catalytic site that is reflected by a number of different Mo(V) EPR signals observed for this enzyme (14). In DMSOR, the polypeptide chain provides a Ser-O- ligand to the Mo, and there may be one or two oxo group ligands in the $\mathrm{Mo}(\mathrm{VI})$ state. In the $\mathrm{FdhH}$, a selenocysteine provides a Se ligand to the Mo, and a hydroxo group is additionally present in the $\mathrm{Mo}(\mathrm{VI})$ state. Primary structure analysis has revealed that FhdH is closely related to the soluble nitrate reductases (2).

Information on the nature of Mo coordination in bacterial nitrate reductases has come from EXAFS and EPR studies (15-18). Comparison of the EXAFS and EPR data on the $P$. denitrificans 1222 NAP with the $E$. coli NAR suggests distinct molybdenum coordination environments in the $\mathrm{Mo}(\mathrm{VI}), \mathrm{Mo}(\mathrm{V})$, and $\mathrm{Mo}(\mathrm{IV})$ oxidation states (17, 18), and primary structure analysis suggested that, while NAP and NAS have a Mo-Cys ligand, NAR has a Mo-Ser ligand (18). The crystal structure of NapA from $D$. desulfuricans has confirmed the presence of the Mo-Cys ligand and has revealed a des-oxo $\mathrm{Mo}(\mathrm{VI})$ state (8). This is clearly at odds with earlier EXAFS studies of the $P$. denitrificans NapAB complex which suggest that it cycles between a Mo(VI) di-oxo species and a Mo(IV) monooxo species (18). Consequently, a more detailed EPR and EXAFS study of $P$. denitrificans NAP has been undertaken. Results are presented which include spectra collected under turnover and inhibited conditions. 
Based upon these data, models for Mo coordination during the catalytic cycle have been formulated, showing that a Mo(IV) mono-oxo to Mo(VI) di-oxo cycle is still favored.

\section{Experimental Procedures}

\section{Purification and Activity Assays.}

P. denitrificans was grown and the NapAB complex purified as described by Berks et al. (5). Enzyme activity was measured under two different conditions. Using dithionite as sole reductant, an estimation of $k_{\text {cat }}$ was obtained by monitoring nitrite accumulation as a function of time using the colorimetric assay described by Snell and Snell (1949) (19). Under these conditions, enzyme activity was "enzyme rereduction limited". Using reduced methyl viologen $\left(\mathrm{MV}^{+}\right)$as electron donor as described in earlier work (20), an estimation for $k_{\text {cat }}$ and $K_{\mathrm{m}}$ was obtained. Under these conditions, turnover was considered not to be rereduction limited, thus permitting the inhibitory effects of azide and cyanide to be studied.

\section{EPR Spectroscopy.}

EPR spectroscopy was performed on an X-band ER200-D spectrometer (Bruker Spectrospin) interfaced to an ESP1600 computer and fitted with a liquid helium flow cryostat (ESR-9; Oxford Instruments). Mo(V) EPR spectra were generally recorded at $60 \mathrm{~K}, \mathrm{ca} .9 .64 \mathrm{GHz}$ microwave frequency, $2 \mathrm{~mW}$ microwave power, and $0.1 \mathrm{mT}$ field modulation amplitude unless otherwise stated in the text or figure legends. Iron-sulfur center and heme EPR were monitored at $10 \mathrm{~K}, 9.64 \mathrm{GHz}$ microwave frequency, $2 \mathrm{~mW}$ microwave power, and $1 \mathrm{mT}$ field modulation amplitude. The spin concentration of samples was determined from integrations of their EPR absorption spectra by comparison to those of a $2 \mathrm{mM} \mathrm{Cu}$ "-EDTA standard as in earlier work (17). EPR simulation was carried out using EPRSim XOP for Igor Pro by John Boswell (Oregon Graduate Institute), which is an adaptation of the program QPOW (21-23). EPR simulations of $\mathrm{Mo}(\mathrm{V})$ species assumed only $I=0 \mathrm{Mo}$ isotopes, and simulations of the $\sim 25 \%$ contribution due to hyperfine coupling to $I=5 / 2{ }^{95 / 97}$ Mo nuclei were not attempted. As the data were only available at $\mathrm{X}$-band, where superhyperfine splittings are included in the simulations, the $\mathbf{g}$ and $\mathbf{A}$ tensors have been taken to be collinear. Where simulations are presented, experimental and simulated spectra are aligned with a magnetic field range corresponding to a microwave frequency of $9.6400 \mathrm{GHz}$.

\section{EPR-Monitored Mediated Redox Potentiometry.}

Redox titrations were carried out at $22^{\circ} \mathrm{C}$ in an anaerobic glovebox where typical oxygen levels were $<1 \mathrm{ppm}$ in a nitrogen atmosphere. Mediated redox potentiometry was performed as described (24), using dithionite and ferricyanide as reductant and oxidant, respectively. Samples were equilibrated at each desired potential for 30 min (longer equilibration times resulted in no further spectroscopic changes); a $150 \mu \mathrm{L}$ sample was anaerobically transferred into an EPR tube, sealed, and frozen immediately in liquid nitrogen.

\section{EXAFS Spectroscopy.}

Molybdenum K-edge X-ray absorption spectra were recorded in fluorescence mode on frozen solutions at $\sim 77 \mathrm{~K}$ on the 5T-wiggler magnet beamline, station 9.2 of the Synchrotron Radiation Source, Daresbury Laboratory, operating at $2 \mathrm{GeV}$ with an average current of $150 \mathrm{~mA}$. A Si (220) double crystal monochromator was used, with the second crystal offset to reject $50 \%$ of the beam in order to minimize harmonic contamination. The fluorescence was monitored using a liquid nitrogen-cooled solid-state 13-element Canberra detector. The monochromator was calibrated at the start of the run using a Mo foil, setting the position of the first peak of the derivative of the foil edge to $19999 \mathrm{eV}$. During multiple scanning of each sample, the edge position did not vary. Each spectrum was collected over $\sim 45 \mathrm{~min}$. 
Table 1: Representative EPR Parameters for Various Signals of NAP and Related EPR Signals from Other Enzymes

\begin{tabular}{|c|c|c|c|c|c|c|c|c|c|c|c|c|}
\hline & & & & & & & & $m T$ & & & & \\
\hline enzyme & signal & $g_{1}$ & $g_{2}$ & $g_{3}$ & $g_{\mathrm{av}}$ & $\begin{array}{l}\text { anisotropy, } \\
g_{1}-g_{3}\end{array}$ & $\begin{array}{l}\text { rhombicity, } \\
g_{1}-g_{2} / g_{1}-g_{3}\end{array}$ & $A_{1}$ & $A_{2}$ & $A_{3}$ & $A_{\mathrm{av}}$ & reference \\
\hline P. denitrificans NAP & Low $g$ [split] & 1.996 & 1.969 & 1.961 & 1.975 & 0.035 & 0.77 & 1.3 & 1.36 & 1.53 & 1.40 & $(17)$ \\
\hline xanthine oxidase & Rapid Type 1 & 1.989 & 1.970 & 1.966 & 1.975 & 0.023 & 0.81 & 1.30 & 0.49 & 0.47 & 0.49 & $(17)$ \\
\hline \multirow[t]{3}{*}{ P. denitrificans NAP } & High $g$ [resting] & 1.9985 & 1.9902 & 1.9806 & 1.9898 & 0.018 & 0.46 & 0.64 & 0.52 & 0.50 & 0.55 & (17) \\
\hline & & & & & & & & $0.28^{b}$ & & & & \\
\hline & High $g$ [azide] & 2.0074 & 1.9940 & 1.9870 & 1.9961 & 0.020 & 0.66 & 0.68 & 0.64 & 0.57 & 0.63 & this study \\
\hline A. vinelandii NAS & High $g$ [nitrate] & 1.9980 & 1.9890 & 1.9810 & 1.9893 & 0.017 & 0.53 & 0.52 & 0.51 & 0.51 & 0.51 & $(40)$ \\
\hline M. formicicum Fdh & CN-treated & 2.005 & 1.998 & 1.989 & 1.997 & 0.016 & 0.44 & 1.05 & 0.85 & 0.88 & 0.93 & $(42)$ \\
\hline P. denitrificans NAP & Very High $g$ & 2.0222 & 1.9993 & 1.9935 & 2.005 & 0.029 & 0.80 & 0.74 & 0.74 & 0.66 & 0.71 & this study (17) \\
\hline A. vinelandii NAS & Very High $g$ & 2.0230 & 1.9981 & 1.9931 & 2.005 & 0.030 & 0.83 & 0.64 & 0.75 & 0.64 & 0.76 & $(40)$ \\
\hline M. formicicum Fdh & Very High $g$ & 2.0200 & 2.0060 & 1.9970 & 2.008 & 0.023 & 0.61 & 0.45 & 0.55 & 0.50 & 0.50 & $(41,42)$ \\
\hline
\end{tabular}

${ }^{a}$ No hyperfine interaction due to coupling of an $I=1 / 2$ nucleus could be resolved in the Low $g$ [unsplit] signal. ${ }^{b}$ Interaction with a second $I=1 / 2$ nucleus in this species could only be resolved in the $g_{1}$ feature. 


\section{Analysis of EXAFS Data.}

The raw data were summed using the Daresbury program EXCALIB, and background subtraction was performed using EXBACK. The isolated $k^{3}$-weighted EXAFS data were analyzed using EXCURV98 (25), employing the singlescattering spherical wave approximation $(26,27)$. Phaseshifts were derived from ab initio calculations using Hedin-Lundqvist potentials and von Barth ground states (28). The theoretical fits were obtained by adding shells of backscattering atoms around the central absorber atom and refining the absorber-scatterer distances, $r$, the Debye-Waller type factors, $2 \sigma^{2}$, and the Fermi energy correction, $E_{f}$, to get the best agreement with the experimental data.

\section{Results}

\section{High g and Low g Mo(V) EPR Signals of the NAP.}

Three types of Mo(V) EPR signal have been previously identified from NAP (Figure 1): High $g$ [resting], High $g$ [nitrate], and Low $g$ [formerly called pseudo-rapid (17)]. The High $g$ [resting] signal can be detected in the 'as prepared' resting enzyme and accounts for $2.5-10 \%$ of the total Mo. It has rhombic character but exhibits unusually low anisotropy (Table 1 ). The signal is split by two weakly interacting $I=1 / 2$ nuclei, $A^{1}{ }_{\text {av }}=0.55 \mathrm{mT}$ and $A^{2}{ }_{1}=0.28 \mathrm{mT}$; the weaker splitting can only be resolved in the $g_{1}$ region. These weak interactions are still apparent in spectra collected from enzyme exchanged into $\mathrm{D}_{2} \mathrm{O}$, suggesting that they do not arise from the protons of $\mathrm{Mo}-\mathrm{OH}$ or $\mathrm{Mo-} \mathrm{OH}_{2}$ groups. Comparison of spectra of $\mathrm{H}_{2} \mathrm{O}$ and $\mathrm{D}_{2} \mathrm{O}$ samples collected at a modulation amplitude of $0.1 \mathrm{mT}$ revealed no difference in the line widths, again consistent with no exchangeable proton groups. Addition of nitrate $(100 \mathrm{mM})$, azide $(100 \mathrm{mM})$, nitrite $(100 \mathrm{mM})$, formate $(100 \mathrm{mM})$, and sulfite (100 $\mathrm{mM}$ ) to this resting enzyme did not alter the form or intensity of the signal even after room-temperature incubation for up to $2 \mathrm{~h}$ (not shown). Furthermore, the signal did not change in the following buffer systems (all at $20 \mathrm{mM}$ ): MES (pH 5.0), HEPES (pH 7.5), Tris-HCl (pH 7.5), phosphate (pH 7.5), Bis-Tris propane (pH 9.5), or CAPS (pH 11.0). 


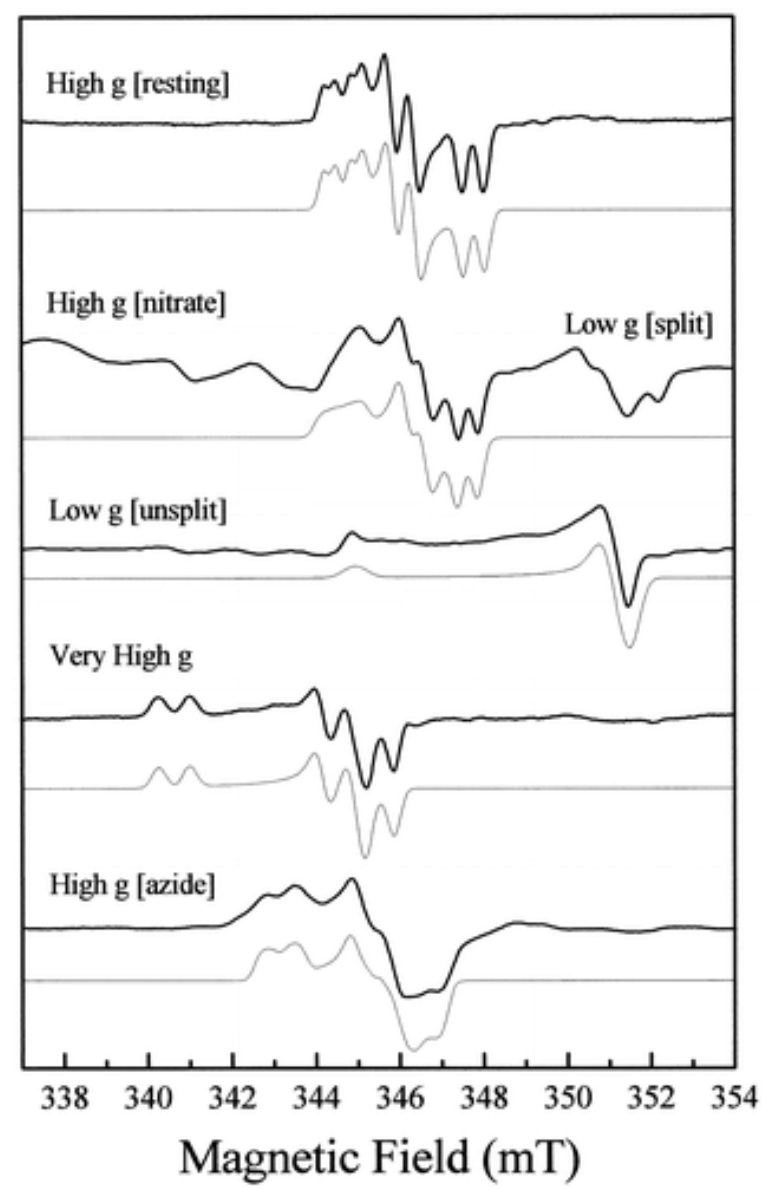

Figure $1 \mathrm{Mo}(\mathrm{V})$ EPR signals of NAP. Faint line spectra in each case are simulations based on the parameters shown in Table 1. Enzyme concentrations were $277 \mu \mathrm{M}$ in $20 \mathrm{mM}$ HEPES, pH 7.2. Conditions of measurement: microwave frequency, $9.64 \mathrm{GHz}$; microwave power, $2 \mathrm{~mW}$; modulation amplitude, $0.1 \mathrm{mT}$; temperature, $60 \mathrm{~K}$.

The High $g$ [nitrate] EPR signal (Figure 1) had been previously detected in samples of nitrate reductase that had been reduced with dithionite and treated with nitrate (17). To see if this EPR signal represents a catalytic intermediate, NAP was studied in turnover using EPR spectroscopy. In these experiments, sodium dithionite was used to reduce NAP directly. In the absence of methyl viologen, the rate of nitrate turnover was determined to be significantly lower $\left(k_{\mathrm{cat}} \sim 1 \mathrm{~s}^{-1}\right)$ compared with methyl viologen-mediated turnover $\left(k_{\mathrm{cat}} \sim 240 \mathrm{~s}^{-1}\right)$. With dithionite as sole reductant, turnover was considered to be "enzyme rereduction limited". This may provide a more accurate representation of physiological turnover than $\mathrm{MV}^{+}$reduction, since in whole cells $k_{\text {cat }}$ has been demonstrated to be approximately $10 \mathrm{~s}^{-1}(29)$, again, significantly slower than the rate obtained using methyl viologen as a redox mediator.

A sample of nitrate reductase was reduced by addition of a $\sim 50$-fold molar excess of dithionite and frozen in liquid $\mathrm{N}_{2}$ within 10 min (Figure $2 \mathrm{~A}$, spectrum b). Following collection of an EPR spectrum, the sample was thawed, a $\sim 360$-fold molar excess of nitrate was subsequently added, the sample was frozen after $10 \mathrm{~s}$ (steady state), and EPR spectra were collected (Figure 2A, spectrum c). The sample was then thawed and incubated for a further period as appropriate and another EPR spectrum acquired. EPR spectra were collected at both $10 \mathrm{~K}$ and $60 \mathrm{~K}$ so that the heme iron, iron-sulfur cluster, and $\mathrm{Mo}(\mathrm{V})$ signals could all be monitored. In spectra collected at $10 \mathrm{~K}$, from the air-oxidized resting NAP, a rhombic low-spin heme signal ( $g=2.9,2.2,1.5 ; \sim 2 \mathrm{~mol}$ of spin $/ \mathrm{mol}$ of NAP) and an oxidized [3Fe-4S] signal ( $g=2.01 ; \sim 0.1 \mathrm{~mol}$ of spin/mol of NAP) could be detected (Figure 2B, spectrum a). It is likely that the [3Fe-4S] ${ }^{+}$signal arose from degradation of the [4Fe-4S] cluster. Following 
reduction with dithionite, the heme signal disappears, and a signal typical of a reduced [4Fe-4S] cluster appears ( $g=2.03,1.94,1.89 ; \sim 1 \mathrm{~mol}$ of spin/mol of NAP) (Figure 2B, spectrum b). The High $g$ [resting] Mo(V) signal decreases slightly in intensity upon reduction but does not change its form (Figure 2A, spectrum b). However, 10 $\mathrm{s}$ after addition of nitrate, the $\mathrm{Mo}(\mathrm{V})$ signal had changed its form and was now more similar to that of the High $g$ [nitrate] species (Figure 2A, spectrum c). Ten minutes after addition of nitrate, the oxidized [3Fe-4S] signal could again be detected (Figure $2 \mathrm{~B}$, spectrum d), and the Mo(V) spectrum was similar to that observed prior to addition of dithionite (Figure 2A, spectrum d). No further change in the spectrum occurred in the next $30 \mathrm{~min}$. It should be noted that the addition of dithionite also resulted in the formation of an Fe"-nitrosyl signal that interferes with the resolution of the $g_{1}$ region of the High $g \mathrm{Mo}(\mathrm{V})$ signal. The bacteria from which the NAP is prepared were grown in the presence of nitrate under anaerobic denitrifying conditions. NO is generated under these conditions, some of which presumably binds to a portion of the NapB hemes and remains tightly bound during purification.

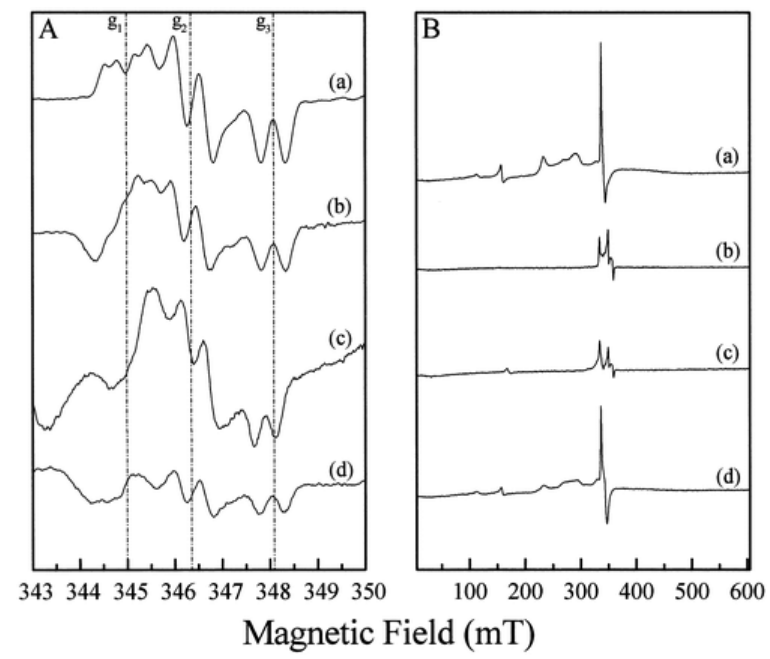

Figure 2 Time-resolved EPR spectra of NAP reduced with $\mathrm{S}_{2} \mathrm{O}_{4}{ }^{2-}$ and during turnover. Panel A: Mo(V) EPR signals. Panel B: Heme and [Fe-S] cluster EPR signals. (a) NAP $(277 \mu \mathrm{M})$ as prepared; (b) reduced with $\mathrm{S}_{2} \mathrm{O}_{4}{ }^{2-}(15 \mathrm{mM})(10$ min incubation); (c) sample (b) frozen $10 \mathrm{~s}$ after the addition of nitrate $(100 \mathrm{mM})$; (d) sample (b) frozen $10 \mathrm{~min}$ after the addition of nitrate (100 mM). Marker lines indicate the $g$-values for the Mo(V) High $g$ [resting] signal. All samples are in $20 \mathrm{mM}$ HEPES, pH 7.2 Conditions of measurement: (A) microwave frequency, $9.64 \mathrm{GHz}$; microwave power, $2 \mathrm{~mW}$; modulation amplitude, $0.1 \mathrm{mT}$; temperature, $60 \mathrm{~K}$; (B) microwave frequency, 9.64 $\mathrm{GHz}$; microwave power, $2 \mathrm{~mW}$; modulation amplitude, $1 \mathrm{mT}$; temperature, $10 \mathrm{~K}$.

Reduction of NAP with a $\sim 50$-fold molar excess of dithionite and prolonged incubation ( $>30 \mathrm{~min}$ ) in the absence of nitrate resulted in a decrease in intensity of the High $g$ [resting] Mo(V) EPR signal and the appearance of a second more axial EPR signal (Low $g$ ) that could be easily resolved from the High $g$ signals by monitoring the $g_{3}$ feature at higher fields (Figure 1 and Figure $3 \mathrm{~A}$ ). The detection of ${ }^{95} \mathrm{Mo},{ }^{97} \mathrm{Mo}$ hyperfine splittings of this signal confirms that it arises from Mo(V) (17). The intensity of the Low $g$ signal increased with time (Figure 3A, spectra b-e). A proportion of the Low $g$ signal was split by a $I=1 / 2$ nucleus (Low $g$ [split]) that was absent when the sample was generated in $\mathrm{D}_{2} \mathrm{O}$. This splitting also disappeared with time, to generate the Low $g$ unsplit signal. This suggests that the $I=1 / 2$ nucleus arises from the proton(s) of a weakly bound water or hydroxide that exchanges with solvent anion (e.g., sulfite produced from dithionite oxidation). The [4Fe-4S] ${ }^{+}$EPR signal did not change during this period of incubation with dithionite (Figure 3B, spectra b-e). 


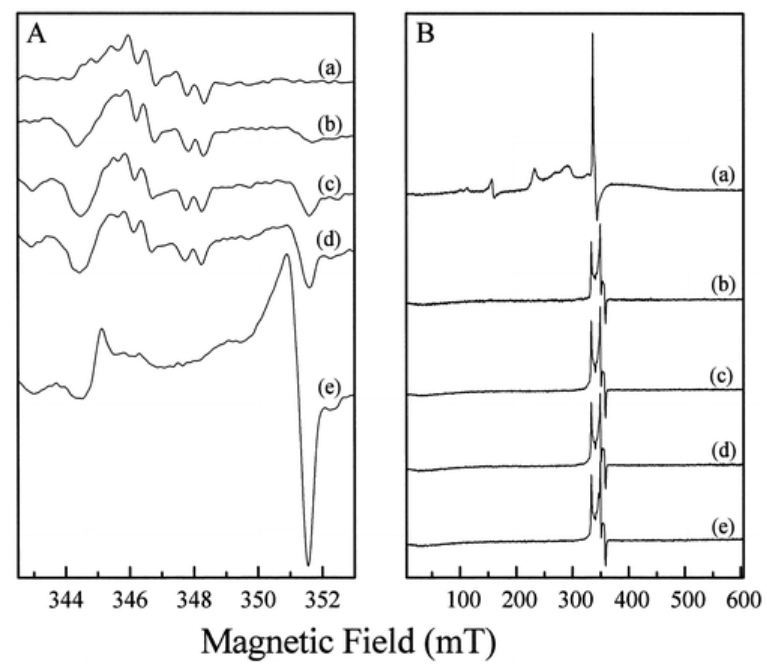

Figure 3 Time-resolved EPR spectra of NAP reduced with $\mathrm{S}_{2} \mathrm{O}_{4}{ }^{2-}$. Panel $\mathrm{A}$ : $\mathrm{Mo}(\mathrm{V})$ EPR signals. Panel B: Heme and [Fe-S] cluster EPR signals. (a) NAP $(277 \mu \mathrm{M})$ as prepared; (b) reduced with $\mathrm{S}_{2} \mathrm{O}_{4}{ }^{2-}(15 \mathrm{mM})$ and frozen after $10 \mathrm{~s}$ incubation; (c) sample (b) frozen after 1 min incubation; (d) sample (b) frozen after 10 min incubation; (e) sample (b) frozen after 30 min incubation. All samples are in $20 \mathrm{mM}$ HEPES, pH 7.2. Conditions were as in Figure 2.

Mediated Redox Potentiometry of the High g [Resting] and Low g Mo(V) EPR Signals. The intensities of the High $g$ [resting] and Low $g$ Mo(V) EPR signals were measured as a function of redox potential in samples withdrawn from mediated redox titrations (Figure 4). The High $g$ [resting] signal initially represented about $10 \%$ of the total Mo and could not be oxidized to Mo(VI) with ferricyanide. This prevented estimation of the midpoint potential of the $\mathrm{Mo}(\mathrm{V} / \mathrm{VI})$ couple for this signal. The decrease in intensity of the $\mathrm{Mo}(\mathrm{V}) \mathrm{High} g$ [resting] signal as a function of redox potential could be fitted to an $n=1$ Nernstian curve from which a midpoint potential of $-123 \mathrm{mV}$ could be derived for the Mo(IV/V) redox couple (Figure 4A). The Low $g$ signal was not detectable at redox potentials above $100 \mathrm{mV}$ and was fully resolved at $-331 \mathrm{mV}$ with an observed $E_{\mathrm{m}}$ for the Low $g \mathrm{Mo}(\mathrm{V} / \mathrm{VI})$ couple of $-159 \mathrm{mV}$ (Figure $4 \mathrm{~B}$ ). The redox titration was not taken below $-400 \mathrm{mV}$, so a titer for the Low $\mathrm{g} \mathrm{Mo}(\mathrm{IV} / \mathrm{V})$ couple was not obtained, though it is clearly of very low potential. Reoxidation of the Low $g$ sample with either nitrate or ferricyanide resulted in the reappearance of the High $g$ [resting] signal. 
A
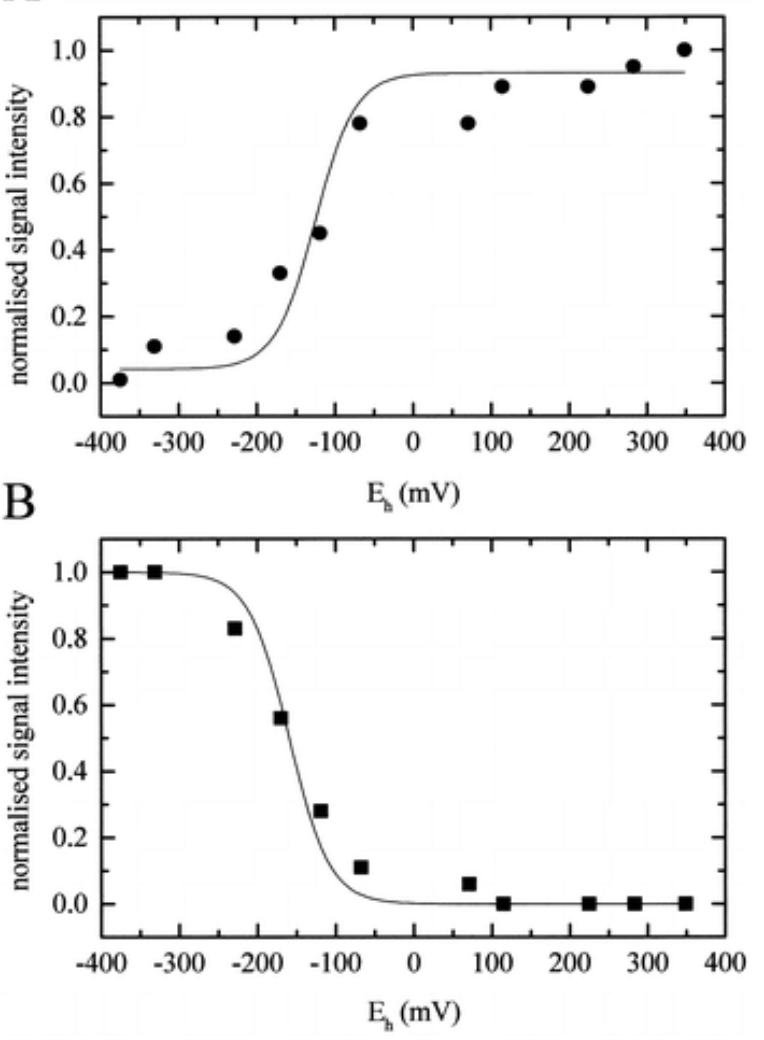

Figure 4 Redox titration of the High $g$ [resting] and Low $g$ Mo(V) EPR signals. Signal intensities were determined from the peak to trough intensity of the $g_{3}$ component of the High $g$ [resting] signal (A) and the peak to trough intensity of the high-field component of the Low $g$ signal (B). Each data set has been normalized to the greatest signal intensity. The solid line in each case shows the best fit with $n=1$ Nernstian components.

\section{K-Edge EXAFS of NAP.}

The 'as prepared' NAP was oxidized with a 10 molar excess of ferricyanide. EPR established that around $5 \%$ of the Mo was in the Mo(V) High $g$ [resting] state, implying that $95 \%$ was in the Mo(VI) state. The Mo K-edge EXAFS of the periplasmic enzyme (Figure $5 \mathrm{~A}$ ) was almost identical to that observed previously with a different enzyme preparation (18). The best fit to the data is with two oxygen atoms at $1.74 \AA$ and four sulfur atoms at $2.43 \AA$, with an additional sulfur atom at $2.82 \AA$ : fits with only one oxo group, or with five sulfurs at the same distance, gave significantly larger residuals (Table 2). The NAP was reduced with a 50-fold excess of dithionite and frozen within $5 \mathrm{~min}$. EPR analysis revealed the presence of a High $g \mathrm{Mo}(\mathrm{V})$ signal that was around $5 \%$ of the total; thus, the sample was assumed to be $95 \% \mathrm{Mo}(\mathrm{IV})$. No significant amount of Low $g \mathrm{Mo}(\mathrm{V})$ signal was present. The best fits to the EXAFS data of this sample (Figure 5B) were obtained with only one oxo group in the coordination sphere (Table 2). The final fit was with one oxygen at $1.74 \AA$, one oxygen at $2.14 \AA$, and three equivalent sulfurs at $2.35 \AA$. The sample was then incubated with excess nitrate for $5 \mathrm{~min}$. The EXAFS of this sample (Figure $5 \mathrm{C}$, Table 2) was very similar to that of the oxidized sample, although the first peak in the Fourier transform, due to the oxo groups, was slightly smaller, which may indicate that the sample contains some mono-oxo species. This would be consistent with the EPR analysis which suggested that about $15 \%$ of the sample was in a Mo(V) state. The best fit was with two oxygens at $1.73 \AA$, four sulfurs at $2.42 \AA$, and one sulfur at $2.88 \AA$. The transition of $\mathrm{Mo}(\mathrm{VI}) \rightarrow \mathrm{Mo}(\mathrm{IV}) \rightarrow \mathrm{Mo}(\mathrm{VI})$ in the three samples was confirmed by the position of the Mo K-edge, which decreased from 20011 to $20008 \mathrm{eV}$ on reduction with dithionite, and returned to $20011 \mathrm{eV}$ on reoxidation with nitrate, illustrated in Figure 6 . The oxidized sample has a distinct preedge feature which is less pronounced in 
the nitrate-reoxidized form, which may be due to the incomplete oxidation of all the molybdenum atoms in the latter sample.
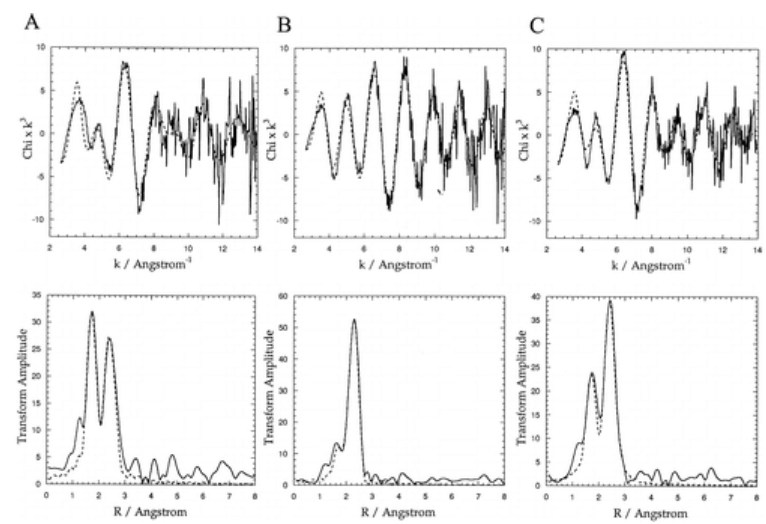

Figure $5 k^{3}$-weighted EXAFS and Fourier transforms of Mo(IV) and Mo(VI) forms of NAP. (A) Ferricyanide oxidized $(\sim 600 \mu \mathrm{M})$. (B) $\mathrm{S}_{2} \mathrm{O}_{4}{ }^{2-}$ reduced $(30 \mathrm{mM})$. (C) Reoxidized with nitrate $(100 \mathrm{mM})$ as substrate. All samples were at $\sim 600 \mu \mathrm{M}$ in $20 \mathrm{mM}$ HEPES, $\mathrm{pH} 7.2$.

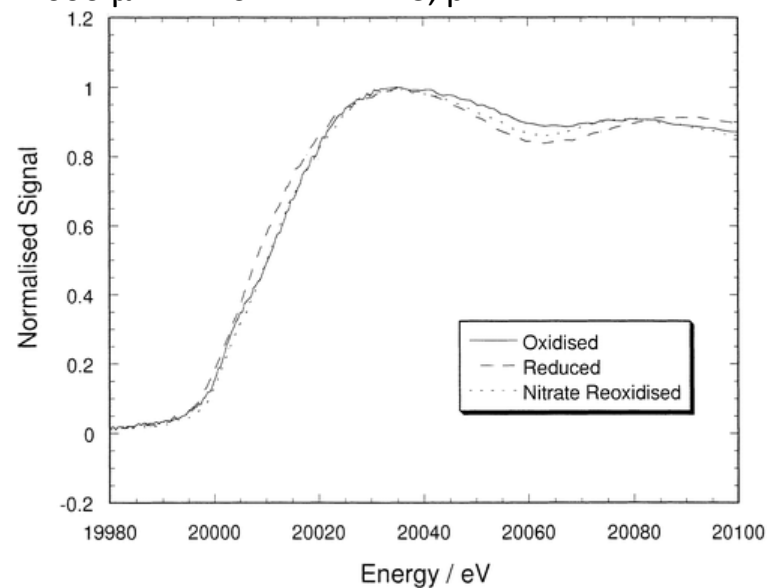

Figure $6 k^{3}$-weighted EXAFS edge positions of Mo(IV) and Mo(VI) forms of the NAP. Edge position relative to Mo foil at $19999 \mathrm{eV}$. Oxidized at $20011 \mathrm{eV}$. Reduced at $20008 \mathrm{eV}$. Nitrate-reoxidized at $20011 \mathrm{eV}$. 
Table 2: Comparison of Various Fits to the EXAFS Data of the Nitrate Reductase Samples ${ }^{a}$

\begin{tabular}{|c|c|c|c|c|c|c|c|c|c|c|c|c|c|}
\hline sample and state $\{$ edge position (eV)\} & $\begin{array}{l}\mathrm{Mo}= \\
\mathrm{O}\end{array}$ & & & $\begin{array}{l}\text { Mo- } \\
\text { O }\end{array}$ & & & $\begin{array}{l}\text { Mo } \\
-S\end{array}$ & & & $\begin{array}{l}\text { Mo } \\
-N\end{array}$ & & & \\
\hline & $n$ & $r(\AA)$ & $2 \sigma^{2}\left(\AA^{2}\right)$ & $n$ & $r(\AA)$ & $2 \sigma^{2}\left(\AA^{2}\right)$ & $n$ & $r(\AA)$ & $2 \sigma^{2}\left(\AA^{2}\right)$ & $n$ & $r(\AA)$ & $2 \sigma^{2}\left(\AA^{2}\right)$ & residual \\
\hline \multirow[t]{5}{*}{ ferricyanide oxidized $\{20011\}$} & 2 & 1.74 & 0.005 & - & - & - & 4 & 2.43 & 0.010 & - & - & - & 45.8 \\
\hline & & & & & & & 1 & 2.82 & 0.022 & & & & \\
\hline & 2 & 1.74 & 0.005 & - & - & - & 4 & 2.43 & 0.010 & - & - & - & 48.6 \\
\hline & 2 & 1.74 & 0.004 & - & - & - & 5 & 2.44 & 0.014 & - & - & - & 55.2 \\
\hline & 1 & 1.74 & -0.002 & - & - & - & 4 & 2.44 & 0.011 & - & - & - & 55.5 \\
\hline \multirow[t]{10}{*}{ dithionite reduced $\{20008\}$} & 1 & 1.74 & 0.007 & 1 & 2.14 & 0.003 & 3 & 2.35 & 0.006 & - & - & - & 38.9 \\
\hline & 1 & 1.74 & 0.007 & 1 & 2.19 & 0.013 & 4 & 2.34 & 0.009 & - & - & - & 39.6 \\
\hline & 1 & 1.73 & 0.008 & - & - & - & 3 & 2.34 & 0.005 & - & - & - & 40.2 \\
\hline & 1 & 1.73 & 0.007 & - & - & - & 4 & 2.34 & 0.008 & - & - & - & 40.3 \\
\hline & 1 & 1.75 & 0.006 & 1 & 2.15 & 0.006 & 2 & 2.34 & 0.002 & - & - & - & 42.0 \\
\hline & & & & & & & 1 & 2.94 & 0.016 & & & & \\
\hline & 2 & 1.74 & 0.019 & - & - & - & 3 & 2.33 & 0.005 & - & - & - & 43.1 \\
\hline & 1 & 1.73 & 0.007 & - & - & - & 5 & 2.34 & 0.011 & - & - & - & 43.6 \\
\hline & - & - & - & 1 & 2.19 & 0.016 & 5 & 2.34 & 0.012 & - & - & - & 52.8 \\
\hline & - & - & - & - & - & - & 5 & 2.34 & 0.011 & - & - & - & 53.4 \\
\hline \multirow[t]{5}{*}{ nitrate turned-over (10 $\min )\{20011\}$} & 2 & 1.73 & 0.009 & - & - & - & 4 & 2.42 & 0.012 & - & - & - & 48.9 \\
\hline & & & & & & & 1 & 2.88 & 0.016 & & & & \\
\hline & 2 & 1.74 & 0.009 & - & - & - & 4 & 2.43 & 0.011 & - & - & - & 51.4 \\
\hline & 2 & 1.73 & 0.010 & - & - & - & 5 & 2.43 & 0.014 & - & - & - & 52.4 \\
\hline & 1 & 1.73 & 0.002 & - & - & - & 5 & 2.44 & 0.015 & - & - & - & 56.1 \\
\hline \multirow[t]{11}{*}{ dithionite reduced + azide $\{20009\}$} & 1 & 1.69 & 0.009 & - & - & - & 3 & 2.31 & 0.006 & 2 & 2.52 & 0.005 & 53.6 \\
\hline & & & & & & & 1 & 2.80 & 0.008 & & & & \\
\hline & 1 & 1.68 & 0.009 & - & - & - & 3 & 2.30 & 0.006 & 1 & 1.91 & 0.046 & 54.4 \\
\hline & & & & & & & 1 & 2.80 & 0.007 & 1 & 2.53 & -0.001 & \\
\hline & 1 & 1.68 & 0.009 & - & - & - & 2 & 2.28 & 0.003 & 2 & 2.51 & 0.001 & 55.4 \\
\hline & & & & & & & 1 & 2.79 & 0.006 & & & & \\
\hline & 1 & 1.70 & 0.009 & - & - & - & 4 & 2.32 & 0.008 & 2 & 2.51 & 0.005 & 56.0 \\
\hline & 1 & 1.70 & 0.010 & - & - & - & 4 & 2.32 & 0.008 & - & - & - & 57.4 \\
\hline & 1 & 1.69 & 0.011 & - & - & - & 4 & 2.32 & 0.008 & 1 & 1.86 & 0.041 & 57.9 \\
\hline & & & & & & & & & & 1 & 2.65 & 0.055 & \\
\hline & 1 & 1.70 & 0.011 & - & - & - & 3 & 2.32 & 0.005 & - & - & - & 58.4 \\
\hline
\end{tabular}




\begin{tabular}{|c|c|c|c|c|c|c|c|c|c|c|c|c|c|}
\hline & 1 & 1.70 & 0.009 & - & - & - & 5 & 2.32 & 0.011 & - & - & - & 58.4 \\
\hline & 2 & 1.71 & 0.024 & - & - & - & 4 & 2.31 & 0.008 & - & - & - & 58.5 \\
\hline \multirow{11}{*}{$\begin{array}{l}\text { ferricyanide- } \\
\text { treated azide sample }\{20009\}\end{array}$} & 1 & 1.69 & 0.007 & - & - & - & 3 & 2.34 & 0.006 & 2 & 2.56 & 0.003 & 51.2 \\
\hline & & & & & & & 1 & 2.76 & 0.013 & & & & \\
\hline & 1 & 1.69 & 0.007 & - & - & - & 4 & 2.35 & 0.009 & 2 & 2.56 & 0.001 & 51.8 \\
\hline & 1 & 1.68 & 0.010 & - & - & - & 3 & 2.34 & 0.003 & 1 & 1.81 & 0.053 & 53.2 \\
\hline & & & & & & & 1 & 2.80 & 0.003 & 1 & 2.56 & -0.005 & \\
\hline & 1 & 1.69 & 0.007 & - & - & - & 4 & 2.35 & 0.008 & - & - & - & 55.2 \\
\hline & & & & & & & 1 & 2.71 & 0.001 & & & & \\
\hline & 1 & 1.70 & 0.008 & - & - & - & 4 & 2.37 & 0.008 & - & - & - & 55.4 \\
\hline & 1 & 1.70 & 0.008 & - & - & - & 5 & 2.37 & 0.010 & - & - & - & 57.1 \\
\hline & 1 & 1.70 & 0.008 & - & - & - & 3 & 2.37 & 0.005 & - & - & - & 57.5 \\
\hline & 2 & 1.72 & 0.023 & - & - & - & 3 & 2.36 & 0.005 & - & - & - & 60.7 \\
\hline \multirow{8}{*}{$\begin{array}{l}\text { ferricyanide- } \\
\text { treated cyanide sample }\{20011\}\end{array}$} & 2 & 1.72 & 0.005 & - & - & - & 3 & 2.35 & 0.011 & - & - & - & 61.4 \\
\hline & & & & & & & 2 & 2.72 & 0.035 & & & & \\
\hline & 2 & 1.71 & 0.004 & - & - & - & 3 & 2.35 & 0.012 & - & - & - & 61.5 \\
\hline & & & & & & & 1 & 2.72 & 0.024 & & & & \\
\hline & 2 & 1.72 & 0.005 & - & - & - & 3 & 2.35 & 0.012 & - & - & - & 62.8 \\
\hline & 2 & 1.72 & 0.005 & - & - & - & 4 & 2.36 & 0.018 & - & - & - & 65.6 \\
\hline & 2 & 1.72 & 0.005 & - & - & - & 5 & 2.37 & 0.024 & - & - & - & 68.5 \\
\hline & 1 & 1.71 & -0.005 & - & - & - & 3 & 2.36 & 0.011 & - & - & - & 68.7 \\
\hline
\end{tabular}

${ }^{a}$ Edge position relative to Mo foil at $19999 \mathrm{eV} . n$ is the number of scatterers $\pm 20 \%$; $r$ is the Mo-scatterer distance $\pm 0.02 \AA ; 2 \sigma^{2}$ is the Debye-Waller factor $\pm 20 \%$. Fits shown in boldface type represent the best fits obtained for each sample. 


\section{Effect of Cyanide and Azide on NAP Enzyme Kinetics.}

NAP was assayed using reduced methyl viologen as electron donor and nitrate as electron acceptor (29). The dependency of the maximum rate on nitrate concentration allowed a $K_{\mathrm{m}}$ of $1.3 \pm 0.2 \mathrm{mM}$ and a $k_{\text {cat }}$ of $240 \pm 32 \mathrm{~s}$ ${ }^{1}$ to be calculated. Despite the rather low $k_{\text {cat }} / K_{\mathrm{m}}$ of $184 \mathrm{mM}^{-1} \mathrm{~s}^{-1}$, NAP is highly specific for its substrate being unable to catalyze reduction of any of the oxyanions of chlorate, iodate, bromate, arsenate, arsenite, formate, tellurite, nitrite, selenite, sulfate, or sulfite. A very low rate of reduction was observed with selenate $\left(1 \mathrm{~s}^{-1}\right)$; however, the high background rate of direct oxidation of $\mathrm{MV}^{+}$by the substrate precluded detailed kinetic studies. Studies on the use of tellurate as a substrate were also compromised by the problem of concomitant direct reduction of the metalloid oxyanion to metallic tellurium, but there was no convincing evidence that tellurate was a substrate for purified NAP. NAP in turnover was sensitive to inhibition by azide and cyanide. The double-reciprocal (1/v vs $1 /[\mathrm{S}]$ ) plot for cyanide inhibition (Figure 7A) shows clearly that cyanide displays noncompetitive inhibition, since there is a distinct decrease in $V_{\max }$ but no significant change in the observed $K_{\mathrm{m}}$ with increasing cyanide concentration. As this type of inhibition demonstrates that cyanide and nitrate do not bind at the same site, it seems unlikely that cyanide is binding directly to the Mo. Azide, in contrast, probably does bind directly to Mo as it displays competitive inhibition (Figure 7B) with the doublereciprocal plot showing $V_{\max }$ remaining constant but an increase in $K_{\mathrm{m}}$ with increasing azide concentration. From these data, the observed $K_{\mathrm{i}}$ for azide was determined to be $11 \pm 1 \mathrm{mM}$, which is much higher than that of 0.02 mM reported for NAR (20).

A
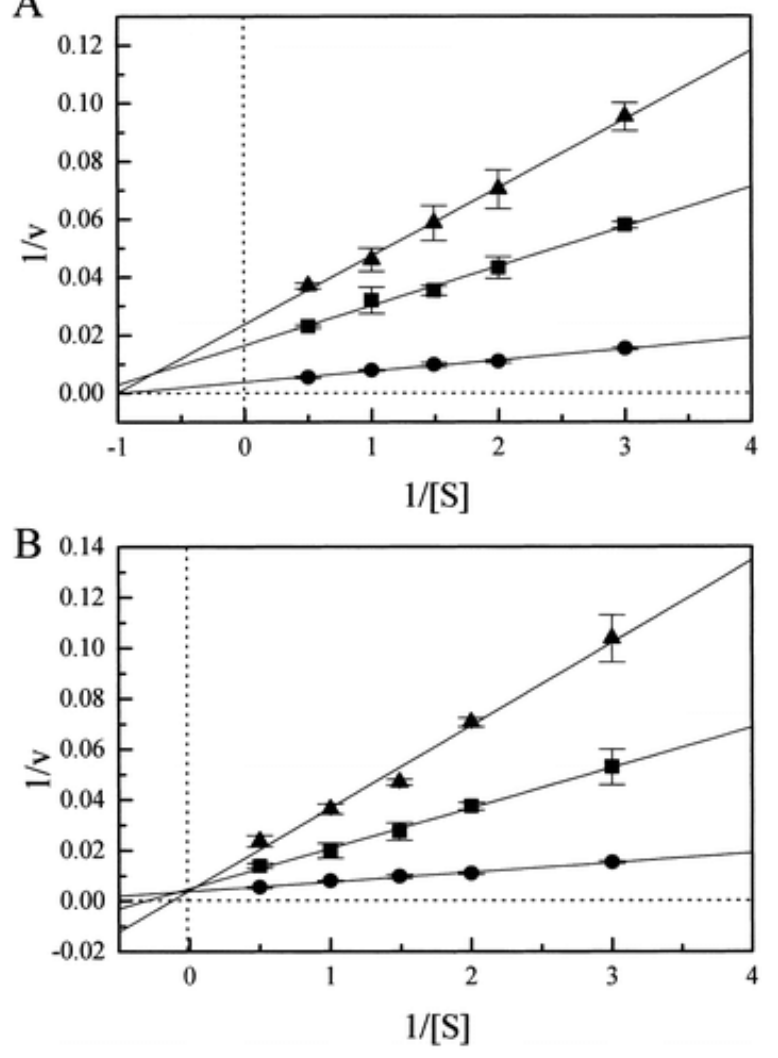

Figure 7 Inhibitory effect of cyanide and azide on NAP activity. Double-reciprocal plots (1/v vs $1 /[S])$ showing noncompetitive $(A)$ and competitive $(B)$ inhibition by cyanide and azide, respectively. Panel $A:(\cdot)$ No inhibitor present; inhibition was measured with [cyanide] at $150 \mu \mathrm{M}(\cdot)$ and $300 \mu \mathrm{M}(\Delta)$. Panel B: (·) No inhibitor present; inhibition was measured with [azide] at $40 \mathrm{mM}(\cdot)$ and $80 \mathrm{mM}(\Delta)$. Enzyme concentration was $0.1 \mu \mathrm{M}$ in $20 \mathrm{mM}$ HEPES, $\mathrm{pH} 7.2$, at $30^{\circ} \mathrm{C}$. The reaction was started by the addition of nitrate, and the reoxidation of methyl viologen was monitored at $600 \mathrm{~nm}$. Each solid line is the best fit where each point represents the mean \pm SD $(n=$ 3). 


\section{Effect of Cyanide and Azide on NAP following Redox Cycling.}

Two distinct Mo(V) EPR signals could be generated in NAP by reducing the enzyme with dithionite, adding either cyanide or azide, and then reoxidizing with ferricyanide, nitrate, or air. The signal observed in cyanide-treated samples has been reported previously and called the Very High $g$ signal (17) and is shown in Figure 1. In the present study, the signal accounted for around $40 \%$ of the total Mo. Efforts to generate this signal by simple $\mathrm{O}_{2}$ oxidation or ferricyanide oxidation were unsuccessful. The Very High $g$ signal has a $g_{\mathrm{av}}>2.00$ (Table 1), which is unusual for a $\mathrm{Mo}(\mathrm{V})$ species. The signal is split by a relatively weak interacting $I=1 / 2$ nucleus $\left(A_{\mathrm{av}}=0.71 \mathrm{mT}\right)$ which remained in spectra collected from enzyme exchanged into $\mathrm{D}_{2} \mathrm{O}$, and no line sharpening was observed. The iron-sulfur cluster and heme signals of the Very High $g$ samples were identical to those of samples containing High $g$ [resting] signals. Upon reduction with dithionite and the addition of nitrate, the Very High $g$ signal disappears and is replaced with a low-intensity High $g$ [nitrate] signal; once the reductant and nitrate have been consumed, the sample returns to the Very High $g$ derivative (Figure 8). Prolonged dialysis of the Very High $g$ sample against buffer not containing cyanide resulted in the removal of the bound cyanide, regenerating a sample that displayed the High $g$ [resting] signal. EXAFS analysis on a reoxidized cyanide-bound sample shows the data to be fitted best with two oxo groups at $1.72 \AA$, three sulfurs at $2.35 \AA$, and two longer sulfurs at $2.72 \AA$. Attempts to fit a bound cyanide with a carbon atom which refined to $1.74 \AA$ and a nitrogen which refined to $3.2 \AA$, including multiple scattering (31) from the linear cyanide group, did not improve the residual (data not shown). The edge position indicates that the molybdenum is in the Mo(VI) state.

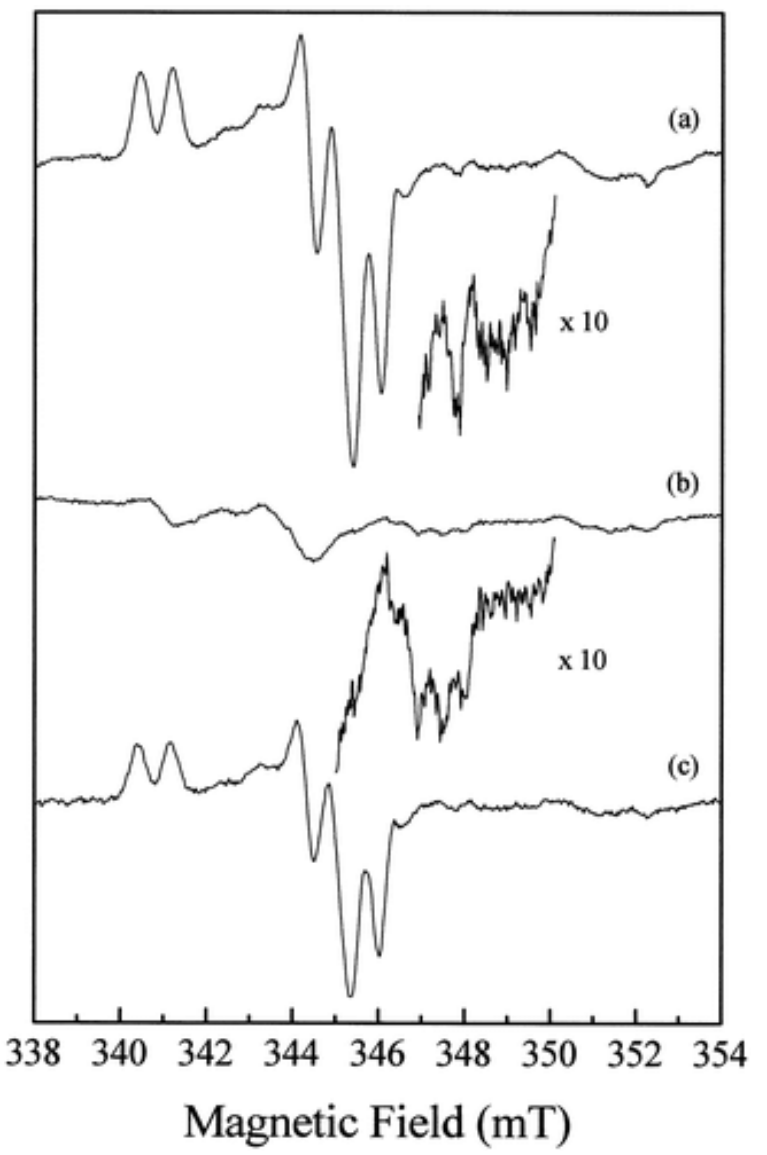

Figure 8 EPR spectra of the Very High $g$ NAP in turnover. (a) Very High $g$; (b) reduced with $\mathrm{S}_{2} \mathrm{O}_{4}{ }^{2-}(50 \mathrm{mM})$ and frozen $1 \mathrm{~min}$ after the addition of nitrate $(100 \mathrm{mM})$; (c) sample (b) frozen $10 \mathrm{~min}$ after the addition of nitrate. All samples are in 20 mM HEPES, pH 7.2. Conditions were as in Figure 1. 
The EPR signal generated by reducing NAP with dithionite in the presence of azide, followed by oxidation to $\mathrm{Mo}(\mathrm{V})$ by ferricyanide, is also shown in Figure 1. This novel spectrum with a $g_{\mathrm{av}}$ of 1.9961 (Table 1) displays Curie temperature dependence. This new signal we have classed as a High $g$ signal and is subsequently referred to as the High $g$ [azide] signal. Like the High $g$ signals, High $g$ [azide] is also split by weakly interacting $I=1 / 2$ nuclei $\left(A_{\mathrm{av}}=0.63 \mathrm{mT}\right)$ which remained in spectra collected from enzyme exchanged into $\mathrm{D}_{2} \mathrm{O}$. Simulation of the spectrum assuming coupled ${ }^{14} \mathrm{~N}$ nuclei did not significantly improve the fit. EPR signals from the oxidized [3Fe$4 \mathrm{~S}$ ] cluster and heme $c$ of the High $g$ [azide] sample were identical to those of samples containing High $g$ [resting] signals. EXAFS analyses of azide-treated samples are shown in Figure 9 and Table 2. Data obtained from a sample of NAP that had been reduced by dithionite to Mo(IV) in the presence of azide show improvement to the fit when two nitrogens ${ }^{2}$ are included in the molybdenum coordination sphere at $2.52 \AA$. However, attempts to simulate the data with the azide bound end-on (nitrogens at 1.9 and $2.9 \AA$, which refined to 1.91 and $2.53 \AA$ ) gave only a slightly worse fit. The azide sample treated with ferricyanide gave a very similar fit to the reduced azide sample, with one rather than two oxo groups in the final fit. The edge positions (Table 2) are consistent with reduced $\mathrm{Mo}(\mathrm{IV})$ rather than oxidized $\mathrm{Mo}(\mathrm{VI})$ for both samples, despite the oxidation of the other cofactors evident from EPR analysis of the ferricyanide-oxidized sample. Supporting evidence for the direct binding of azide to Mo was provided by electron nuclear double resonance (ENDOR) spectroscopy of NAP treated with ${ }^{15} \mathrm{~N}$-labeled azide (Butler, C. S., Richardson, D. J., and Lowe, D. J., unpublished results).
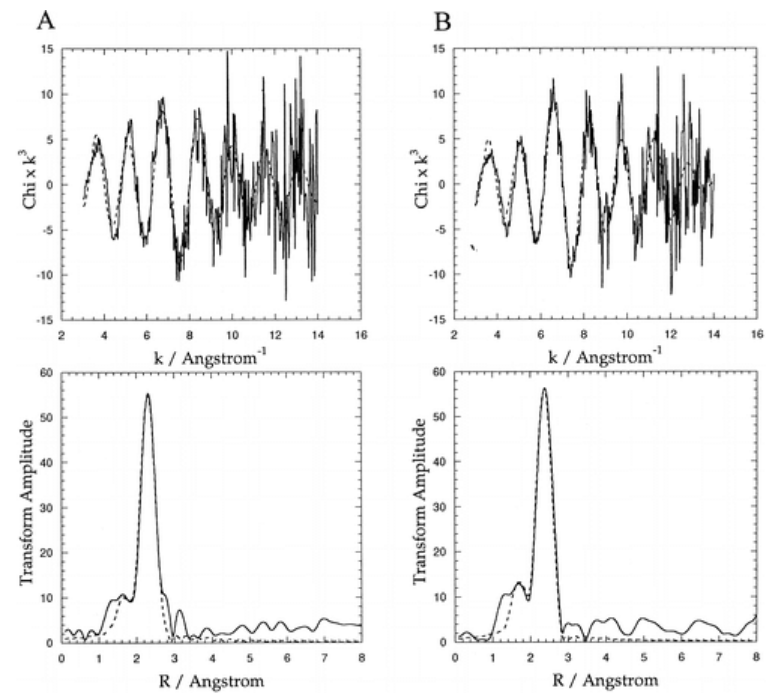

Figure $9 k^{3}$-weighted EXAFS and Fourier transform of the Mo(IV) form of NAP with bound azide. (A) Reduced; (B) ferricyanide-treated. All samples were at $\sim 600 \mu \mathrm{M}$ in $20 \mathrm{mM}$ HEPES, pH 7.2.

\section{Discussion}

Previous EPR studies on the periplasmic nitrate reductase identified several distinct signal-giving Mo(V) species (17). Here we have undertaken a more detailed characterization of these species during turnover and describe a novel additional signal generated by azide treatment. This further spectroscopic analysis together with the recent three-dimensional structure determination of other proteins that, in common with the periplasmic nitrate reductase, bind the (MGD) ${ }_{2}-\mathrm{Mo}$ (bis-MGD) cofactor allows us to propose structures for these species and suggest their relationships to one another and to the catalytic cycle.

The crystal structures of the periplasmic DMSO/TMAO reductases $(9-11,13)$, the selenocysteine-containing formate dehydrogenase-H of $E$. coli (12), and the recently published structure of NAP from $D$. desulfuricans (8) show that the oxidized molybdenum atom in enzymes with a bis-MGD cofactor normally has 4-fold sulfur coordination provided by the dithiolene/dithiolate group of each MGD cofactor. A further ligand is provided by 
an amino acid side chain, serine in the case of the DMSO/TMAO reductases and selenocysteine in formate dehydrogenase-H. Additional oxo/hydroxo/water ligands may also be present. The crystal structure of NapA from $D$. desulfuricans (8) has confirmed the earlier predictions based on amino acid sequence comparisons (2, 4), that the molybdenum amino acid ligand in periplasmic nitrate reductases is a cysteine residue (Cys 140 in the $D$. desulfuricans enzyme and Cys 181 in the $P$. denitrificans enzyme). Thus, the periplasmic nitrate reductase from $P$. denitrificans is likely to have a maximum of five sulfur ligands to the molybdenum(VI) atom. This would be compatible with the K-edge EXAFS data presented here. The EXAFS data also strongly indicate that upon reduction with dithionite, three sulfur ligands and a single oxo $(=0)$ group are coordinated to the molybdenum atom in the $\mathrm{Mo}(\mathrm{IV})$ state and that reoxidation by nitrate produces a di-oxo $\mathrm{Mo}(\mathrm{VI})$ coordinated by five sulfur ligands. With respect to the mono-oxo to di-oxo cycle, the $P$. denitrificans periplasmic nitrate reductase resembles that of the oxidized and reduced crystal forms of $R$. capsulatus DMSO reductase solved by the Bailey group (11) and the closely related TMAO reductase of Shewanella massilia (13). This mode of coordination is different from that shown by Romāo and co-workers (8), who have modeled the structure of NAP from $D$. desulfuricans as being $\mathrm{Mo}(\mathrm{VI})$ with a water/hydroxo ligand. Based upon their oxidized structure, they have proposed that the enzyme cycles between des-oxo Mo(IV) and mono-oxo $\mathrm{Mo}(\mathrm{VI})$, which is then readily protonated to form the water/hydroxo ligand. Such a mechanisim is similar to that proposed for Fdh from E. coli. It should be noted that, based on primary sequence homology, NAP from $D$. desulfuricans is more closely related to Fdh from $E$. coli than is NAP from $P$. denitrificans. Furthermore, unlike NAP from $P$. denitrificans, NAP from $D$. desulfuricans has been demonstrated to have low levels of formate dehydrogenase activity (8). The possibility exists that the subtle differences between the two enzymes may account for different oxygen coordination at Mo during the catalytic cycle. In fact, variation in the number of bound Mo oxo groups for similar enzymes, isolated from different hosts, is not unprecedented. Both Garton et al. (1997) and George et al. (1996) have argued, based on Resonance Raman (32) and EXAFS (33) data, respectively, that the active site Mo of $R$. sphaeroides DMSO reductase cycles between mono-oxo Mo(VI) and des-oxo Mo(IV) forms throughout the catalytic cycle. This is consistent with the crystal structure of $R$. sphaeroides DMSO reductase by Schindelin et al. (9), who have modeled the oxidized enzyme as mono-oxo Mo(VI). However, the two crystal structures of the analogous enzyme DMSO reductase isolated from $R$. capsulatus $(10,11)$, with supporting evidence from EXAFS studies (34), show this DMSO reductase to cycle between mono-oxo Mo(IV) and di-oxo Mo(VI).

The EXAFS data presented suggest that upon reduction by dithionite two sulfur atoms, presumably from one pterin, are lost from the coordination sphere of $\mathrm{Mo}(\mathrm{IV})$, but religate following reoxidation by nitrate. The change in the coordination of the pterins to the Mo is most interesting and suggests that it is an essential part of the catalytic cycle under the slow turnover conditions studied here, possibly allowing nitrate to be easily accommodated into the Mo coordination sphere. The lability of one of the pterin dithiolene ligands was also observed by Schindelin et al. (1996) for the crystal structure of reduced DMSO reductase from $R$. sphaeroides (9); this together with the present study strongly suggests that the pterin can cycle "on" and "off" reversibly during enzyme turnover with dithionite as reductant, in which turnover is re-reduction limited.

To extend the EXAFS models to the EPR-detected Mo(V) species, it is informative to note that the observed $\mathrm{Mo}(\mathrm{V})$ signals fall into three groupings characterized by distinct and widely separated $g_{\mathrm{av}}$ values: Very High $g$, High $g$, and Low $g$ (Table 1). The most common and best documented change in the molybdenum coordination sphere that gives rise to such $g_{\text {av }}$ shifts is variation in the number of sulfur ligands. A correlation between increasing sulfur coordination and increasing $g_{\text {av }}$ is evident from model compound studies $(35,36)$, and a decrease in $g_{\text {av }}$ also accompanies the Mo-SH $\rightarrow \mathrm{Mo}-\mathrm{OH}$ transition seen in molybdopterin-containing hydroxylases (36). Thus, the number of sulfur ligands coordinating the molybdenum atom might be expected to increase in the order Low $g$, High $g$, and Very High $g$. With these considerations in mind, we can now examine each signal-giving species in detail. 
The Low g Signals.

The periplasmic nitrate reductase Low $g$ signals have a similar $g_{a v}$ to the Rapid Type I signal of xanthine oxidase (Table 1). Indeed, the two signals are so similar overall (Table 1) that Low $g$ was originally termed 'Pseudo-Rapid' (17). Crystallographic characterization of xanthine oxidase-like aldehyde oxidoreductase from Desulfovibrio gigas suggests that the Rapid EPR signal corresponds to a state in which the molybdenum is ligated by three sulfur ligands (the dithiolate of a single molybdopterin molecule and a terminal thiol group) and a terminal oxo group, in addition to the weakly coordinated substrate molecule $(37,38)$. The similarities between periplasmic nitrate reductase Low $g$ and xanthine oxidase Rapid signals probably indicate similar coordination environments of the molybdenum atoms, and so by analogy the core coordination of Low $g$ is three sulfur ligands together with a terminal oxo group. Given that the fully reduced Mo(IV) species is coordinated by three sulfur ligands, we suggest that the Low $g \mathrm{Mo}(\mathrm{V})$ species is also only coordinated by three sulfur ligands, the dithiolene/dithiolate of the remaining molybdopterin molecule and the Cys 181 sulfur. Since this species is observed after prolonged incubation with dithionite or by redox-mediated potentiometry at potentials below $-150 \mathrm{mV}$, it would seem likely that the loss of one of the pterin molecules results in a significant drop in the midpoint potential of the $\mathrm{Mo}(\mathrm{IV} / \mathrm{V})$ couple. Consequently, the Low $g \mathrm{Mo}(\mathrm{V})$ becomes EPR-detectable. In support of this assignment, it should be noted that the periplasmic DMSO reductases, like periplasmic nitrate reductase, can give High $g$ and Low $g \mathrm{Mo}(\mathrm{V})$ species (14). The Low $g$ DMSO reductase signal is very similar to that of the desulfo form of xanthine oxidase in which the terminal thiol group is lost and the molybdenum atom has only the two sulfur ligands of the single molybdopterin cofactor (37). The DMSO reductase Low $g$ species can thus probably be assigned to the crystal form in which the molybdoperin is coordinated by a single MGD cofactor. Xanthine oxidase Rapid ( $\left.g_{\mathrm{av}} 1.976\right)$ is related to desulfo xanthine oxidase Slow ( $\left.g_{\mathrm{av}} 1.964\right)$ by the addition of a molybdenum sulfur ligand. By analogy, periplasmic nitrate reductase Low $g$ ( $g_{\text {av }} 1.973$ ) should have one more molybdenum sulfur ligand than DMSO reductase Low $g\left(g_{\mathrm{av}} 1.965\right)(14)$. This is entirely reasonable given the replacement of the serine molybdenum ligand in DMSO reductase by cysteine in the periplasmic nitrate reductase. A final molybdenum ligand in Low $g$ [split] can be assigned to hydroxo/water on the basis of the exchangeable proton in the molybdenum coordination sphere. Low $g$ [unsplit] lacks the proton splitting, and we suggest that in this species the hydroxo/water ligand is replaced by an anion derived from the buffer solution, perhaps a dithionite oxidation product or a buffer component (Figure 10). 


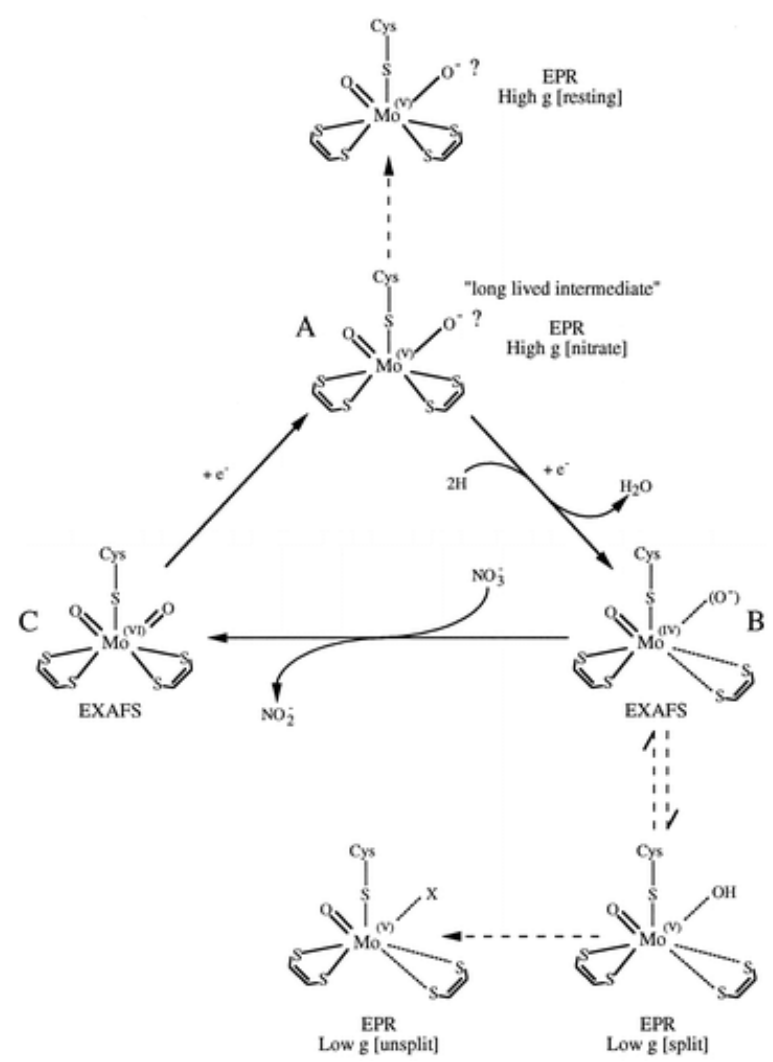

Figure 10 Proposed catalytic cycle for NAP. (A) High $g$ [nitrate]; (B) reduced to Mo(IV) mono-oxo with loss of coordinating pterin; $(\mathrm{B}-\mathrm{C})$ binding of $\mathrm{NO}_{3}{ }^{-}$and oxidation to $\mathrm{Mo}(\mathrm{VI})$ di-oxo with release of $\mathrm{NO}_{2}^{-}$; $(\mathrm{C}-\mathrm{A})$ oneelectron reduction to form $\mathrm{Mo}(\mathrm{V}) \mathrm{High} g$ [nitrate]. Cycle continues. In the absence of reductant and substrate, $\mathrm{Mo}(\mathrm{V}) \mathrm{High} g$ [nitrate] reverts to High $g$ [resting]. See text for the possible origin of O?

\section{The High g Signals.}

The High $g$ [resting] species is always present (2.5-10\% of Mo) in 'as prepared' air-oxidized enzyme, and its concentration does not change significantly during turnover of the enzyme. The signal only changes slightly in intensity between 0 and $>+400 \mathrm{mV}$ even though the periplasmic nitrate reductase catalytic site is likely to operate within this potential range. It is completely insensitive to $\mathrm{pH}$ and addition of exogneous ligands, including the substrate (nitrate), product (nitrite), and the inhibitors (azide and cyanide). On the basis of these observations, we suggest that it represents a species that is not normally on the catalytic cycle. In contrast, the High $g$ [nitrate] signal is only observed during turnover in the presence of nitrate and is a transient signal that only persists during the period in which the enzyme is in turnover. We therefore suggest that the High $g$ [nitrate] signal arises from a relatively long-lived catalytic intermediate. Because the High $g \mathrm{Mo}(\mathrm{V})$ species only represents approximately $2.5-10 \%$ of the sample, no direct evidence for the coordinating ligands for these species can be obtained by EXAFS spectroscopy. We can therefore only speculate that both High $g$ [nitrate] and High $g$ [resting] have four sulfur ligands provided by the two pterins and a fifth sulfur ligand from the coordinating cysteine residue. As argued above, EXAFS analysis suggests that the High $g$ species must have at least a single terminal oxo group.

Were the High $g$ species to contain a hydroxo/water as an additional molybdenum ligand, we would expect to observe magnetic interactions from a strongly coupled proton exchangeable in deuterated water in the Mo(V) EPR spectrum. The High $g$ signals do show splitting from two weakly coupled $I=1 / 2$ nuclei, presumably protons, but these spectral features are still present in High $g$ [resting] following exchange into deuterated water and therefore do not arise from a hydroxo/water group. Instead we suggest that these interactions originate from 
the methylene protons of the putative cysteinate ligand. George (1985) has argued that the protons of a bound hydroxo in the high-pH forms of sulfite oxidase and membrane-bound nitrate reductase are difficult to detect by EPR because the magnetic coupling is anisotropic and because $\mathbf{g}$ and $\mathbf{A}$ are noncollinear (39). However, a proton that could be ascribed to a bound hydroxyl cannot be detected from the High $g$ [resting] species by ENDOR (Lowe, D. J., Butler, C. S., and Richardson, D. J., unpublished results). It is thus highly unlikely that either High $g$ [resting] or High $g$ [nitrate] has a hydroxo/water ligand. We can also probably exclude the possibility that High $g$ [resting] has a vacant coordination site because the EPR signal was, almost uniquely for molybdoenzymes, completely unperturbed by high concentrations of potentially strong exogenous ligands, including the enzyme substrate nitrate. By analogy, High $g$ [nitrate] also lacks a hydroxo/water ligand, or a vacant coordination site. Since the High $g$ [nitrate] is only observed during the reductive half-cycle, between $\mathrm{Mo}(\mathrm{VI})$ dio-oxo and Mo(IV) mono-oxo, it is also unlikely that it has nitrate or nitrite bound; we therefore suggest that both High $g$ [nitrate] and High $g$ [resting] are coordinated either by an additional oxy - $\mathrm{O}^{-}$or - $\mathrm{O}-\mathrm{X}$ group prior to protonation to yield water. That may be stabilized by electrostatic interactions with the positively charged arginine residue ( $\operatorname{Arg} 354, D$. desulfuricans numbering) that has been implicated from the crystal structure (8) to anchor the bound substrate. Because the EPR parameters of the High $g$ [resting] and High $g$ [nitrate] signals are so similar, their underlying structures must be closely related and differ only as a consequence of small changes in the catalytic pocket. This may be induced by the presence of substate/product during turnover and only affect coordination geometery, not coordination number. A catalytic model for the periplasmic nitrate reductase based upon the data obtained using dithionite as the sole electron donor, incorporating the inferred $\mathrm{Mo}(\mathrm{VI}), \mathrm{Mo}(\mathrm{V})$ High $g$ [nitrate], High $g$ [resting], and Mo(IV) states, is given in Figure 10.

\section{Very High g Signals.}

As indicated in Table 1 the High $g$ [nitrate] and Very High $g$ Mo(V) EPR signals of periplasmic nitrate reductase are remarkably similar to signals previously detected in the assimilatory nitrate reductase of Azotobacter vinelandii (40) and the selenocysteine-independent formate dehydrogenase of Methanobacterium formicicum $(41,42)$. Note that within the family of proteins binding bis-MGD cofactors, the periplasmic nitrate reductase catalytic subunit forms a sequence subgroup with the bacterial assimilatory nitrate reductases and formate dehydrogenases (2). In contrast to the periplasmic nitrate reductase, the Mo(V) EPR signal found in the 'as prepared' assimilatory nitrate reductase is Very High $g$ rather than High $g$ even though the enzyme was not exposed to cyanide during purification. In the assimilatory nitrate reductase, a High $g$ [nitrate] signal can be generated from Very High $g$ by treatment with dithionite and nitrate. Following dithionite removal by enzyme turnover, the High $g$ signal appears to relax back to Very High $g$ on extended incubation. The different pathways by which the Very High $g$ and High $g$ signals are produced in the two types of water-soluble bacterial nitrate reductases need tobe taken into account when suggesting models for these two species. In the $M$. formicicum formate dehydrogenase, a Mo(V) signal resembling Very High $g$ can be generated by the addition of dithionite or formate to the resting state (Table 1) (41). Treatment of the oxidized enzyme with cyanide results in the generation of a High $g$-like signal (Table 1) (42). This conversion is accompanied by the release of one thiocyanate molecule per molybdenum atom, suggesting that cyanide has removed a terminal sulfur atom from the molybdenum coordination sphere.

Taken together (i) the noncompetitive nature of cyanide inhibition of periplasmic nitrate reductase activity, (ii) the lack of evidence for cyanide coordination to the molybdenum in the EXAFS spectrum of cyanide-treated enzyme, and (iii) the presence of Very High $g$ signals in bacterial assimilatory nitrate reductase not exposed to cyanide all suggest that cyanide does not coordinate directly to the molybdenum atom of Very High $g$.

Furthermore, the conversion between Very High $g$ and High $g$-like signals in formate dehydrogenase induced by loss of a terminal sulfur ligand would seem to suggest that the Very High $g$ species represents a species with one 
more sulfur ligand than the High $g$ species. This is clearly at odds with the EXAFS data presented, which show the best fit with Mo coordinated by two oxo groups and five sulfur ligands. However, the binding of cyanide in the active site pocket causes a change in the Mo coordination geometry, resulting in a significant distortion of the bond lengths of the coodinating sulfurs, which may account for the elevated EPR $g$ values.

\section{Azide Signal.}

The combined evidence from the kinetic analysis and the EPR, ENDOR, and EXAFS spectroscopies demonstrates that the High $g$ [azide] EPR spectrum arises from a Mo(V) species in which azide is bound directly to the molybdenum. Although, azide has been demonstrated to inhibit the membrane-bound nitrate reductase (20), this study is the first demonstration of direct coordination of azide to the metal center of a molybdopterincontaining enzyme. The EXAFS data suggest that azide binds to Mo(IV), a process which may be aided by the displacement of one of the pterin sulfur ligands. The inability of this inhibited Mo species to reoxidize to Mo(VI) upon treatment with ferricyanide suggests that the binding of azide has stabilized Mo(IV) and Mo(V) states, possibly by blocking religation of the pterin dithiolene ligands. This is of particular interest as it provides further support for a catalytic mechanism invoking redox-linked changes in pterin coordination.

In conclusion, the results presented herein have focused on determining active site structures involved during the "enzyme rereduction limited" catalytic cycle of the periplasmic nitrate reductase. Our data strongly suggest that under these conditions, the periplasmic nitrate reductase from $P$. denitrificans cycles between a mono-oxo $\mathrm{Mo}(\mathrm{IV})$ and di-oxo $\mathrm{Mo}(\mathrm{VI})$ species. The possible lability of one of the pterin dithiolene ligands may also play an important role in catalysis by allowing substrate binding and/or modulating redox potential. These results, together with the identification of a novel Mo(V) [azide] species, demonstrate that the active site of NAP, centered at the molybdenum, is highly flexibly and can accommodate some variability both in the type and in the number of ligands in the Mo coordination sphere. It is now of interest to extend these models by studying the enzyme in rapid-turnover, during $\mathrm{MV}^{+}$-driven reduction, using the rapid-freeze-quench technique at the millisecond time scale required. This in combination with the use of site-directed mutagenesis may soon provide further information on this interesting class of enzymes.

\section{Acknowledgment}

We are grateful to Mr. Jeremy Thornton for help with the purification of NAP and to Dr. Jacqueline Farrar and Dr. Myles Cheesman for assistance with the EPR equipment. We thank Prof. M. J. Romāo for providing the manuscript on the $D$. desulfuricans NAP crystal structure prior to publication.

\section{References}

1 Sears, H. J., Little, P. J., Richardson, D. J., Spiro, S., Berks, B. C., and Ferguson, S. J. (1997) Arch. Microbiol. 167, 61-66.

2 Berks, B. C., Ferguson, S. J., Moir, J. W. B., and Richardson, D. J. (1995) Biochim. Biophys. Acta1232, 97-173.

3 Ludwig, W., Mittenhuber, G., and Freidrich, C. G. (1993) Int. J. Syst. Bacteriol.43, 363-367.

4 Berks, B. C., Richardson, D. J., Reilly, A., Willis, A. C., and Ferguson, S. J. (1995) Biochem. J. 309, 983-992.

5 Berks, B. C., Richardson, D. J., Robinson, C., Reilly, A., Aplin, R. T., and Ferguson, S. J. (1994) Eur. J. Biochem. 220, 117-124.

6 Breton, J., Berks, B. C., Reilly, A., Thomson, A. J., Ferguson, S. J., and Richardson, D. J. (1994) FEBS Lett. 345, 76-80.

7 Richardson, D. J., Sears, H. J., Spiro, S., Berks, B., and Ferguson, S. J. (1997) in Advances en el Metabolismo del Nitrogeno: de la Fistologia a la Biologia Molecular (Vega, J. M., Pedro, J. A., Castillo, F., and Maldonado, J. M., Eds.) Universidad de Sevilla, Secretariado de Publicacions.

8 Dias, J. M., Than, M. E., Humm, A., Huber, R., Bourenkov, G. P., Bartunik, H. D., Bursakov, S., Calvete, J., Caldeira, J., Carneiro, C., Moura, J. J. G., Moura, I., and Romāo, M. J. (1999) Structure 7, 65-79. 
9 Schindelin, H., Kisker, C., Hilton, J., Rajagopalan, K. V., and Rees, D. C. (1996) Science272, 1615-1621.

10 Schneider, F., Löwe, J., Huber, R., Schindelin, H., Kisker, C., and Knäblein, J. (1996) J. Mol. Biol.263, 53-69.

11 McAlpine, A. S., McEwan, A. G., Shaw, A. L., and Bailey, S. (1997) J. Biol. Inorg. Chem.2, 690-701.

12 Boyington, J. C., Gladyshev, V. N., Khangulov, S. V., Stadtman, T. C., and Sun, P. D. (1997) Science 275, 1305-1308.

13 Czjzek, M., Dos Santos, J. P., Pommier, J., Giordano, G., Méjean, V., and Haser, R. (1998) J. Mol. Biol.284, 435-447.

14 Bennett, B., Benson, N., McEwan, A. G., and Bray, R. C. (1994) Eur. J. Biochem.225, 321-331.

15 George, G. N., Bray, R. C., Morpeth, F. F., and Boxer, D. H. (1985) Biochem. J.227, 925-931.

16 George, G. N., Turner, N. A., Bray, R. C., Morpeth, F. F., Boxer, D. H., and Cramer, S. P. (1989) Biochem. J.259, 693-700.

17 Bennett, B., Berks, B. C., Ferguson, S. J., Thomson, A. J., and Richardson, D. J. (1994) Eur. J. Biochem. 226, 789-798.

18 Bennett, B., Charnock, J. M., Sears, H. J., Berks, B. C., Thomson, A. J., Ferguson, S. J., Garner, C. D., and Richardson, D. J. (1996) Biochem. J. 317, 557-563.

19 Snell, F. D., and Snell, C. T. (1949) Colorimetric Methods of Analysis, Vol. 2, pp 802-807, Van Nostrand, New York.

20 Craske, A. L., and Ferguson, S. J. (1986) Eur. J. Biochem. 158, 429-436.

21 Belford, R. L. (1979) EPR Syposium, 21st Rocky Mountain Conference, Denver, CO.

22 Nilges, M. J. (1979) Ph.D. Thesis, University of Illinois.

23 Maurice, A. M. (1980) Ph.D. Thesis, University of Illinois.

24 Dutton, P. L. (1978) Methods Enzymol. 54, 411-435.

25 Binsted, N. (1998) Daresbury Laboratory EXCURV98 programme.

26 Lee, P. A., and Pendry, J. B. (1975) Phys. Rev. B11, 2795-2811.

27 Gurman, S. J., Binsted, N., and Ross, I. (1984) J. Phys. C17, 143-151.

28 Hedin, L., and Lundqvist, S. (1969) Solid State Phys.23, 1-181.

29 Richardson, D. J., and Ferguson, S. J. (1992) Arch. Microbiol. 157, 535-537.

30 Jones, R. W., and Garland, P. B. (1977) Biochem. J.164, 199-211.

31 Gurman, S. J., Binsted, N., and Ross, I. (1986) J. Phys. C: Solid State Phys.19, 1845-1861.

32 Garton, S. D., Hilton, J., Oku, H., Crouse, B. R., Rajagopalan, K. V., and Johnson, M. K. (1997) J. Am. Chem. Soc.119, 12906-12916.

33 George, G. N., Hilton, J., and Rayagopalan, K. V. (1996) J. Am. Chem. Soc.118, 1113-1117.

34 Baugh, P. E., Garner, C. D., Charnock, J. M., Collison, D., Davies, E. S., McAlpine, A. S., Bailey, S., Lane, I., Hanson, G. R., and McEwan, A. G. (1997) J. Biol. Inorg. Chem.2, 634-643.

35 Chang, C. S. J., Collison, D., Mabbs, F. E., and Enemark, J. H. (1990) Inorg. Chem.29, 2261-2267.

36 Dowerah, D., Spence, J. T., Singh, R., Wedd, A. G., Wilson, G. L., Farchione, F., Enemark, J. H., Kristofzki, J., and Bruck, M. (1987) J. Am. Chem. Soc. 109, 5655-5665.

37 Huber, R., Hof, P., Duarte, R. O., Moura, J. J. G., Moura, I., Liu, M. Y., LeGall, J., Hille, R., Archer, M., and Romāo, M. J. (1996) Proc. Natl. Acad. Sci. U.S.A.93, 8846-8851.

38 Romāo, M. J., Archer, M., Moura, I., Moura, J. J. G., LeGall, J., Engh, R., Schneider, M., Hof, P., and Huber, R. (1995) Science 270, 1170-1176.

39 George, G. N. (1985) J. Magn. Reson. 64, 384-394.

40 Gangeswaran, R., Lowe, D. J., and Eady, R. R. (1993) Biochem. J. 289, 335-342.

41 Barber, M. J., Siegel, L. M., Schauer, N. L., May, H. D., and Ferry, J. G. (1983) J. Biol. Chem. 258, 10839-10845.

42 Barber, M. J., May, H. D., and Ferry, J. G. (1986) Biochemistry 25, 8150-8155.

1 Abbreviations: MGD, molybdopterin guanine dinucleotide; EPR, electron paramagnetic resonance; ENDOR, electron nuclear double resonance; EXAFS, extended X-ray absorption fine structure; NAP, periplasmic nitrate reductase; NAR, membrane-bound nitrate reductase; NAS, assimilatory nitrate reductases; Fdh, 
formate dehydrogenase; DMSOR, dimethyl sulfoxide reductase; TMAO, periplasmic trimethylamine $\mathrm{N}$ oxide reductase; $\mathrm{MV}^{+}$, methyl viologen radical.

2 It should be noted that EXAFS cannot readily distinguish between scatterers of similar atomic numbers such as chlorine and sulfur or nitrogen and oxygen. Consequently, coordination of the nitrogens of azide cannot be distinguished from that of additional oxygen ligands. Therefore, assignment of a bound azide molecule is suggestive only and cannot be confirmed by this technique alone. 